\title{
Spotlight on measles 2010: An epidemiological overview of measles outbreaks in Poland in relation to the measles elimination goal
}

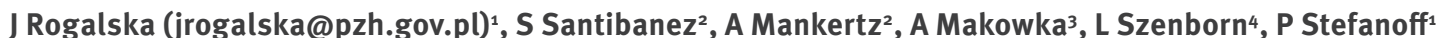

1. Department of Epidemiology, National Institute of Public Health - National Institute of Hygiene (NIZP-PZH), Warsaw, Poland

2. Regional Reference Laboratory WHO EURO, Robert Koch Institute, Berlin, Germany

3. Department of Virology, National Institute of Public Health - National Institute of Hygiene (NIZP-PZH), Warsaw, Poland

4. Department of Pediatric Infectious Diseases, Medical University, Wrocław, Poland

Citation style for this article:

Citation style for this article: Rogalska J, Santibanez S, Mankertz A, Makowka A, Szenborn L, Stefanoff P. Spotlight on measles 2010: An epidemiological overview of measles outbreaks in Poland in relation to the measles elimination goal. Euro Surveill. 2010;15(17): pii=19549. Available online: http://www.eurosurveillance.

org/ViewArticle.aspx?Articleld=19549

This article has been published on 29 April 2010

The objective of this study was to describe transmission chains of measles observed in Poland during 2008-2009. A decade ago, the incidence of measles in Poland declined and approached one case per million inhabitants one of the World Health Organization's criteria for measles elimination. Following a period of very few reported measles cases (2003 to 2005), an increase in incidence was observed in 2006. Since then, the incidence has constantly exceeded one case per million inhabitants. Of 214 measles cases reported in 2008 and 2009 in Poland, 164 (77\%) were linked to 19 distinct outbreaks, with $79 \%$ of cases belonging to the Roma ethnic group. Outbreaks in the non-Roma Polish population had different dynamics compared to those in the Roma population. On average, measles outbreaks in Roma communities involved 10 individuals, seven of whom were unvaccinated, while outbreaks in the non-Roma Polish population involved five individuals, half of whom were incompletely vaccinated. The majority of outbreaks in Roma communities were related to importation of virus from the United Kingdom. In six outbreaks, the epidemiologic investigation was confirmed by identification of genotype D4 closely related to measles viruses detected in the United Kingdom and Germany. Our data indicate that Poland is approaching measles elimination, but measles virus circulation is still sustained in a vulnerable population. More efforts are needed to integrate the Roma ethnic group into the Polish healthcare system and innovative measures to reach vulnerable groups should be explored.

\section{Background}

In 1998 Poland implemented a measles elimination programme, coordinated by the World Health Organization (WHO) Regional Office for Europe. It requires monitoring consecutive stages of the elimination by tracking secondary outbreak cases, genotyping of detected measles viruses (MV) and serological testing of all suspected cases of measles [1].

Measles has been a notifiable disease in Poland since 1919. National case-based notification was initiated in 1996 and WHO case definitions [2] have been adopted. Since 2005, the case classification of the European Union [3] has been used. The first dose of the monovalent measles vaccine for children aged 13-15 months was introduced in Poland in 1975, and the second dose for seven year old children was implemented in 1991. In 2005 the monovalent measles vaccine was replaced by the combined measles-mumps-rubella (MMR) vaccine, administered at the age of 13-15 months and 10 years.

Poland belongs to the European countries with moderate incidence of measles $[4,5]$. Following the introduction of routine immunisation, the incidence of measles has decreased. From 2003 to 2005 the number of locally acquired cases in Poland was below the elimination threshold of one case per million inhabitants. Since 2006 the measles incidence has increased and remained continuously above this elimination indicator (Figure 1) [6]. In 2006, measles cases were mostly related to importation of MV-D4, whereas MV-D6 was detected in 2007. In 2008-2009 a substantial increase in the frequency of outbreak-related cases was observed, often related to importation.

The vaccine coverage in Poland with MMR vaccine remains well above the target of $>95 \%$ for the first dose of measles vaccine (MCV1), another WHO marker for measles elimination [7]. Coverage with the first dose of MMR vaccine in three-year-olds in 2008 was $98.4 \%$, and for two doses of MMR in eleven-year-olds it was $97.2 \%$. Information on measles vaccine coverage in ethnic groups such as the Roma ethnic minority is not available in Poland. 
The objective of this study was to describe the patterns of chains of transmission investigated in Poland between 1999 and 2009, with special focus on 20082009 , in relation to the measles elimination goal.

\section{Methods}

In the present study, measles cases reported within the Polish enhanced measles surveillance between
1999 and 2009 were investigated. Physicians were required to report all suspected measles cases to the local health departments and to obtain samples for confirmatory IgM testing. The information collected during case investigation included demographic characteristics, vaccination status, and clinical and laboratory data. Although not routinely collected in the national surveillance system, the ethnic background

\section{FIGURE 1}

Secular trends of measles incidence in Poland, 1966-2009

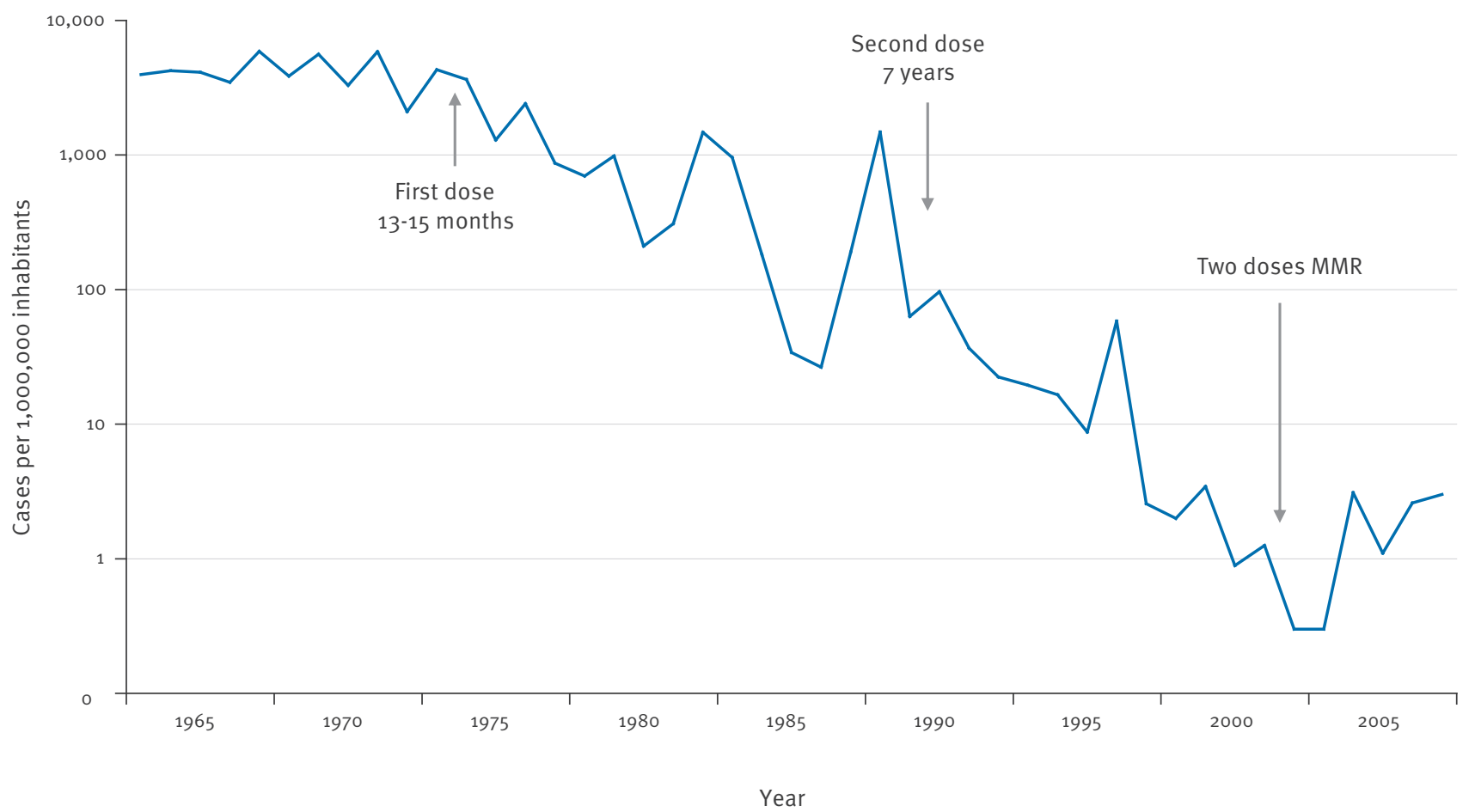

\section{FIGURE 2}

Number of reported measles cases, including those which could be linked to transmission chain, Poland, 1999-2009 ( $\mathrm{n}=784$ )

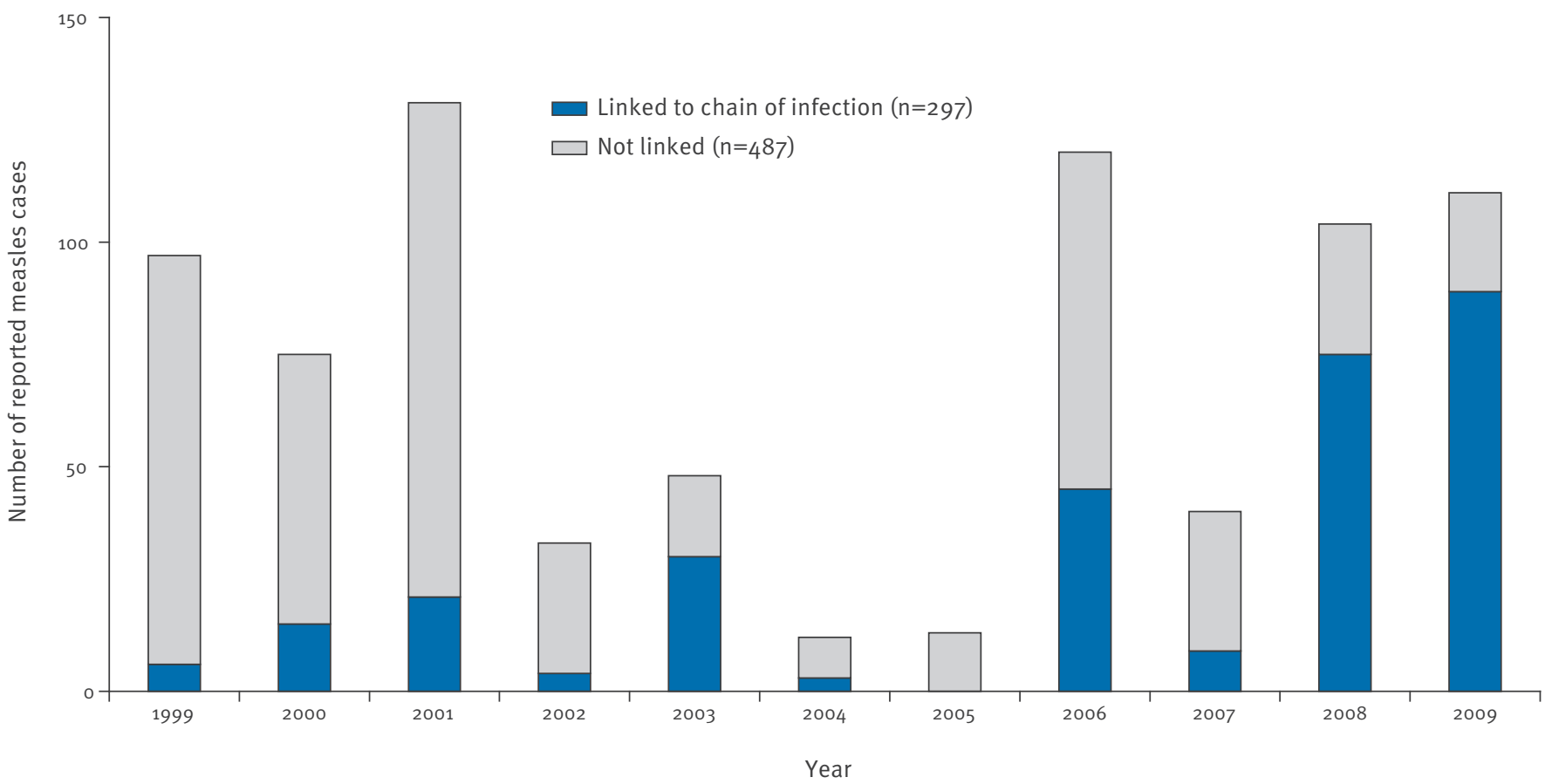


of reported measles cases was recorded. Contact tracing is routinely undertaken, especially for unvaccinated and exposed individuals. Serological testing and detection of measles virus RNA are performed in the National Reference Laboratory at the National Institute of Public Health. Measles virus-containing samples are sent to the WHO Regional Reference Laboratory for Measles and Rubella (Robert Koch Institute, Berlin) for genotyping.

For the present study, we defined an imported outbreak as resulting from importation of measles virus by a person arriving from abroad who was exposed and developed symptoms outside Poland, and subsequently was the source of documented local transmission to other cases linked to the outbreak. If available, genotyping results were used for confirmation of importationrelated transmission chains.

Measles case reports from 1999 to 2009 are described. Measles cases with an established link to the infection transmission chain (outbreak cases) in 2008-2009 are described in more detail to determine the role of disease importation and outbreak patterns.

\section{Results}

Over time, an increasing proportion of measles cases could be linked to identified chains of transmission in Poland (Figure 2), from 6\% in 1999 to $80 \%$ in 2009. Of 569 cases of measles reported between 1999 and
2007, 133 (23\%) were linked to outbreaks. In 2008 and 2009 , this proportion was higher, with $77 \%$ reported measles cases linked to outbreaks.

During 2008 and 2009, 19 measles outbreaks with 164 cases were reported in Poland. Seven outbreaks were due to importation of the disease from the United Kingdom (UK), and 12 involved only indigenous transmission. Outbreaks in that period were reported from nine of the 16 provinces of Poland. One of the 164 outbreak cases, excluded from further analysis, occurred in a Ukrainian citizen who arrived in Poland in February 2009. He contracted measles while staying in a hospital where an outbreak occurred.

Fifty-three percent of cases in 2008 and 2009 were female and $90.2 \%$ of the patients were residents of urban areas. Cases were seen in all age groups, although adults aged over 19 years were predominantly affected (45 cases, $27.4 \%$ ). One hundred and thirty patients (79.3\%) were admitted to hospital. The proportion of hospitalised cases was highest in children aged five to nine years (90.9\%). Seventy-nine percent of all outbreak-related cases during 2008 and 2009 occurred among the Roma ethnic group.

Important differences were observed between the outbreaks among the Roma community and those occurring in non-Roma Polish population (Table).

TABLE

Characteristics of cases linked to chain of transmission, Poland, 2008-2009 (n=163)

\begin{tabular}{|c|c|c|c|c|c|c|}
\hline \multirow{2}{*}{ Characteristic } & \multicolumn{2}{|c|}{ Roma } & \multicolumn{2}{|c|}{ Non-Roma Polish population } & \multicolumn{2}{|c|}{ Total } \\
\hline & $\mathbf{N}$ & $\%$ & $\mathbf{N}$ & $\%$ & $\mathbf{N}$ & $\%$ \\
\hline Number of outbreaks & 13 & 68.4 & 6 & 31.6 & 19 & 100.0 \\
\hline \multicolumn{7}{|l|}{ Sex } \\
\hline Female & 64 & 50.8 & 23 & 62.2 & 87 & $53 \cdot 4$ \\
\hline Male & 62 & 49.2 & 14 & 37.8 & 76 & 46.6 \\
\hline \multicolumn{7}{|l|}{ Confirmation of cases } \\
\hline Laboratory-confirmed & 72 & 57.1 & 35 & 94.6 & 107 & 65.6 \\
\hline Epidemiologically linked & 54 & 42.9 & 2 & 5.4 & 56 & 34.4 \\
\hline \multicolumn{7}{|l|}{ Vaccination status } \\
\hline Vaccinated according to age & 18 & $14 \cdot 3$ & 12 & 32.4 & 30 & 18.4 \\
\hline Incompletely vaccinated & 91 & 72.2 & 18 & 48.6 & 109 & 66.9 \\
\hline \multicolumn{7}{|c|}{ Importation status (number of outbreaks) } \\
\hline Import-related & $\begin{array}{c}7 \\
\text { (68 cases) } \\
\end{array}$ & $\begin{array}{l}53.8 \\
(54.0) \\
\end{array}$ & $\begin{array}{c}1 \\
\text { (3 cases) }\end{array}$ & $\begin{array}{l}16.7 \\
(8.1) \\
\end{array}$ & $\begin{array}{c}8 \\
\text { (71 cases) }\end{array}$ & $\begin{array}{c}42.1 \\
(43.6) \\
\end{array}$ \\
\hline Local & $\begin{array}{c}6 \\
\text { (58 cases) }\end{array}$ & $\begin{array}{c}46.2 \\
(46.0)\end{array}$ & $\begin{array}{c}5 \\
\text { (34 cases) }\end{array}$ & $\begin{array}{l}83.3 \\
(91.9) \\
\end{array}$ & $\begin{array}{c}11 \\
\text { (92 cases) }\end{array}$ & $\begin{array}{r}57.9 \\
(56.4) \\
\end{array}$ \\
\hline \multicolumn{7}{|c|}{$\begin{array}{l}\text { Generations of transmission identified } \\
\text { (number of outbreaks) }\end{array}$} \\
\hline $1-2$ & 9 & 69.2 & 4 & 66.7 & 13 & 68.4 \\
\hline 3 or more & 4 & 30.8 & 2 & $33 \cdot 3$ & 6 & 31.6 \\
\hline D4 genotype identified & $\begin{array}{c}4 \\
\text { (19 cases) }\end{array}$ & $\begin{array}{c}30.8 \\
(15.1 \%) \\
\end{array}$ & $\begin{array}{c}2 \\
\text { (2 cases) }\end{array}$ & $\begin{array}{l}33 \cdot 3 \\
(5.4) \\
\end{array}$ & $\begin{array}{c}6 \\
\text { (21 cases) }\end{array}$ & $\begin{array}{c}31.6 \\
(12.9) \\
\end{array}$ \\
\hline
\end{tabular}


Outbreaks among Roma were considerably larger with an average of 10 cases, who were mostly unvaccinated ( $72 \%$ of outbreak cases), while outbreaks in the nonRoma Polish population involved an average of five cases, with $48 \%$ of outbreak cases incompletely vaccinated. The majority of outbreaks in Roma communities were related to importation of virus from the UK. In six outbreaks, measles virus genotyping identified a genotype D4 strain that was most closely related to viruses from the UK and Germany. Figure 3 presents the exact genetic relationship between viruses isolated from outbreak cases in 2008 and 2009 to closely related strains isolated in other countries. Laboratory testing was performed more often for cases from the non-Roma Polish

\section{FIGURE 3}

Phylogenetic analysis of measles viruses of genotype D4 detected from 2006 to 2009 in Poland and other European countries

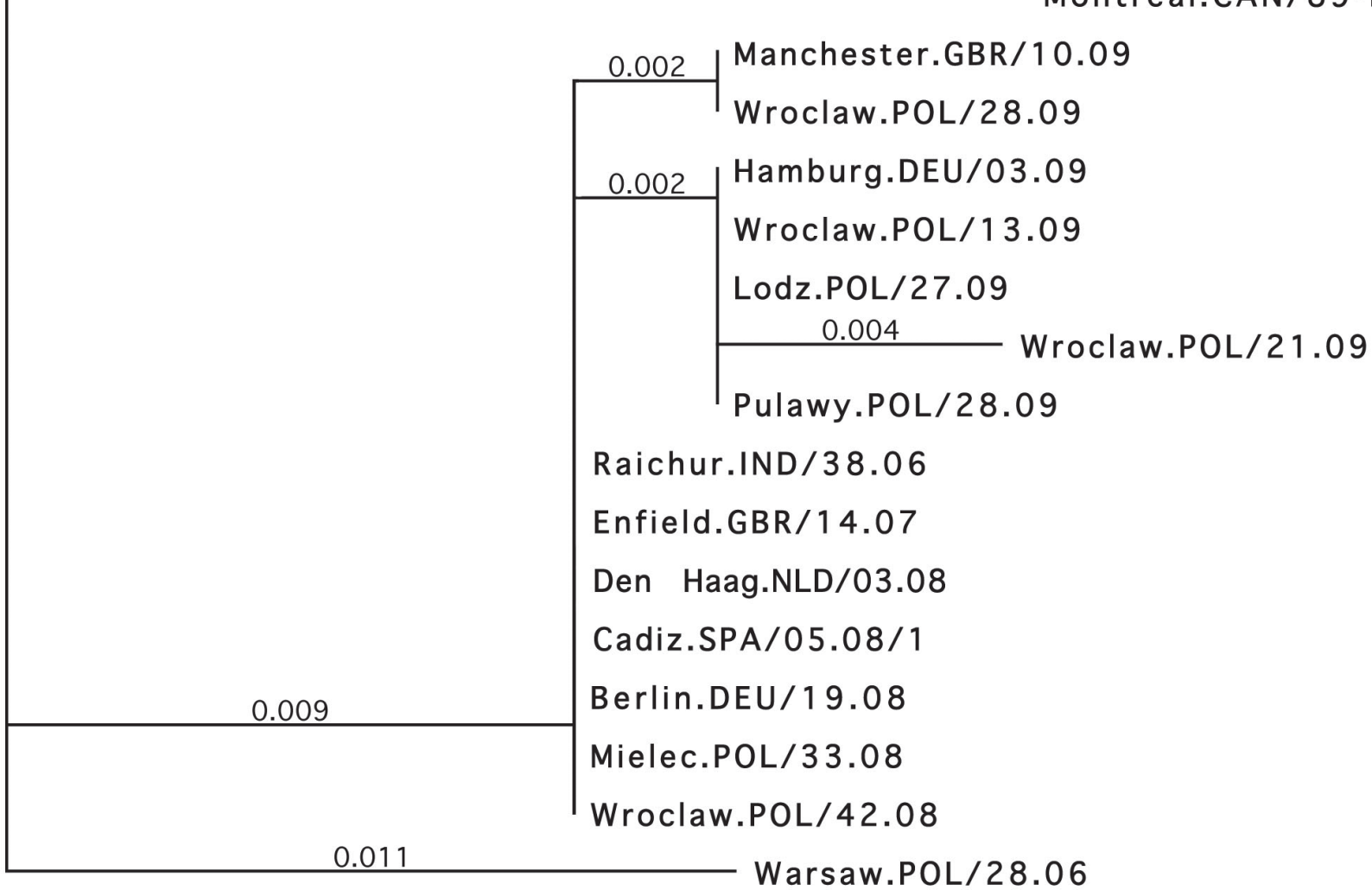

0.002

The phylogenetic tree is based on a 456 nt sequence encoding the carboxyterminus of the nucleoprotein. It includes all measles strains identified in Poland in 2006-2009 and world strains most closely related to them.

Method: Neighbor Joining; Best Tree; tie breaking = Systematic.

Distance: Tamura-Nei; Gamma correction = Off; Gaps distributed proportionally.

Source: Robert Koch Institute, Berlin, Germany.

\section{FIGURE 4}

Number of reported measles cases by week of illness onset, Poland, 2009

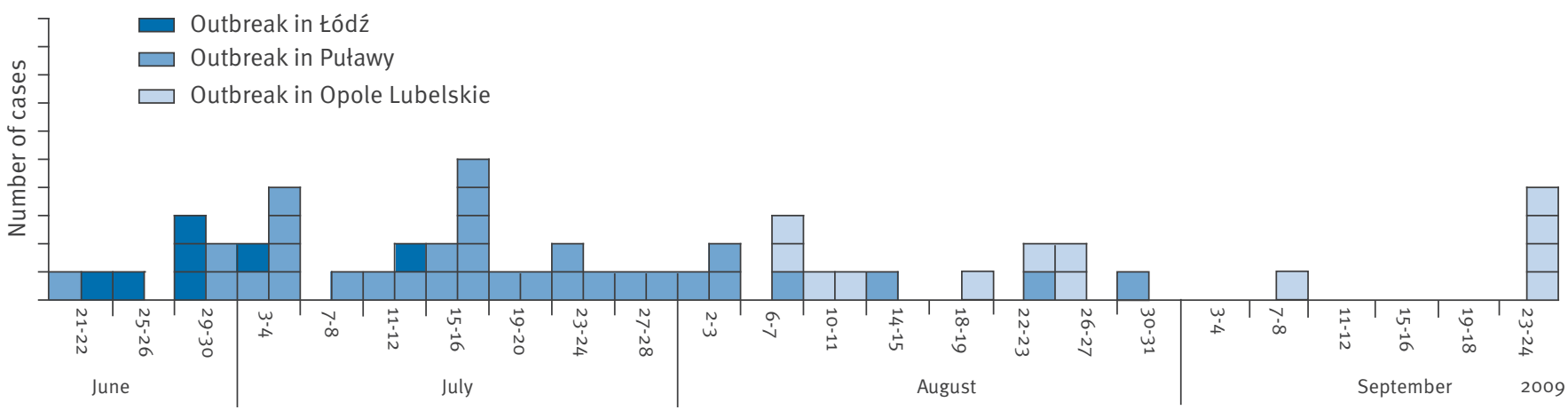


population (94\%) than for cases from the Roma community ( $57 \%)$. Based on the dates recorded for onset of disease, the same proportion of outbreaks recorded up to four generations of transmission among the Roma and non-Roma Polish population.

In some cases, separate outbreaks could be linked by detailed epidemiological and molecular investigation. From August to October 2008 two outbreaks occurred in Mielec and Wroclaw, which are approximately 400 $\mathrm{km}$ apart. A total of 32 cases were recorded from those two outbreaks in Roma communities, and both could be linked to the strain Enfield/GBR/14.07 (Accession No. EF600554) of measles virus genotype D4. The index cases were among families with young children returning from London, UK. In the same period numerous importations from England, confirmed by the detection of the Enfield strain, were notified in several other European countries (Figure 3), i.e. the Netherlands (Den Haag.NLD/03.08, GenBank Accession No. EU 585844), Spain (Cadiz.SPA/05.08/1, GenBank Accession No. EU982301) and Germany (Berlin.DEU/19.08).

From June to October 2009, 54 cases were linked to three outbreaks in Roma communities living in different towns (Figure 4). The first outbreak with seven measles cases was reported in the city of Lodz. Subsequently, 47 measles cases were reported in the city of Pulawy and Opole Lubelskie in Lubelskie province. The outbreaks in Lodz and Pulawy were linked by epidemiological investigation and measles virus genotyping, since the measles virus detected in Lodz and Pulawy was identical to the strain Hamburg/DEU/03.09(D4) observed in northwest Germany in the first quarter of 2009. The outbreak in Opole Lubelskie was linked to the Pulawy outbreak by an epidemiological link, and no samples were collected for genotyping.

\section{Discussion}

Measles outbreaks have recently been described in many European countries. Large outbreaks were reported in 2008 and 2009 in France [8], Switzerland [9], and Bulgaria [10].

WHO defined measles elimination as a situation in a large geographical area in which endemic transmission of measles virus cannot occur and imported measles cases do not initiate sustained transmission [11]. Despite public health efforts and maintaining high levels of vaccination coverage, outbreaks due to measles virus importation continue to occur in Poland. Similarly as in other European countries, herd immunity has not been achieved despite a national measles vaccination coverage above $95 \%$. This failure is possibly related to the existence of specific vulnerable populations, who are often not reached by the public health services regarding vaccination. Common causes of limited access to public health services may involve particular attitudes or beliefs of these populations [12-14].
There could be several reasons for the increased proportion of cases for which a chain of infection could be traced in 2008 and 2009, compared with the previous period. On the one hand, local public health officers may have been investigating the epidemiological links more efficiently during the recent years. When approaching the measles elimination phase, it becomes more important to monitor infection chains and, if necessary, to intervene. On the other hand, well defined outbreaks were identified in 2008 and 2009 with several cases occurring in the same households. This rather indicates an appearance of pockets of unvaccinated persons, who are sustaining measles transmission, possibly in relation to anti-immunisation beliefs, or poor access to healthcare.

Similar to other European countries, Poland has not succeeded in controlling measles enough to reach one case per million inhabitants, one of the WHO criteria for measles elimination. In recent years, most outbreaks in Poland were detected in ethnic minorities and were often related to measles importation from the United Kingdom or Germany. Currently, the emphasis of measles elimination activities should be directed to immunising all sections of the population that are not adequately protected. Considering that ethnic minorities are often marginalised and discriminated against, we need to better understand the health problems, attitudes and beliefs of these communities. An assessment performed during a large outbreak in August 2009, revealed limited access to healthcare and low life expectancy of a settled Roma community [15]. Both in Roma and in the non-Roma Polish population, a considerable proportion of unvaccinated cases in the under 19-year-olds indicates the need to address at least some high-risk groups in Poland. The best approach would be to focus on healthcare workers and persons working in crowded environments like schools, universities or airports.

Genetic characterisation of detected measles viruses has been done in Poland continuously since 2006 [16]. Molecular and epidemiological investigation of the recent outbreaks revealed five independent transmission chains with a duration of under three months. Genetic data demonstrated a close relationship of four of the five distinct subvariants of genotype $D_{4}$ identified in Poland to viruses of western Europe (GenBank Accession No. EF600554, EU585844, EU982301, GQ370461) from where they were imported, and to a virus from India (GenBank Accession No. EU812270) considered to be the source of the recent European D4 viruses [Regional Reference Laboratory WHO EURO, Robert Koch Institute, personal communication]. The present analyses document that Poland has made progress on its way to reach the elimination goal for measles virus in the WHO European region. Considering increasing airline travel, and anti-vaccination beliefs, continuous efforts are necessary to maintain a high vaccination status of the Polish population, and implement innovative measures to reach vulnerable groups. 


\section{References}

1. World Health Organization, Regional Office for Europe. Strategic plan for measles and congenital rubella infection in the WHO European Region. Copenhagen, WHO Regional Office for Europe, 2003. Available from: http://www.euro.who.int/ document/e81567.pdf

2. World Health Organization, Regional Office for Europe. Surveillance guidelines for measles and congenital rubella infection in the WHO European Region. Copenhagen, WHO Regional Office for Europe, 2003. Available from: http://www. euro.who.int/document/E82183.pdf

3. Commission Decision 2003/534/EC amending Decision No 2119/98/EC of the European Parliament and of the Council and Decision 2000/96/EC as regards communicable diseases listed in those decisions and amending Decision 2002/253/ EC as regards the case definitions for communicable diseases. Available from: http://eur-lex.europa.eu/LexUriServ/ LexUriServ.do?uri=0J:L:2003:184:0035:0039:EN:PDF

4. Muscat M, Bang H, Wohlfahrt J, Glismann S, Mølbak K; EUVAC. NET Group. Measles in Europe: an epidemiological assessment. Lancet. 2009;373(9661):383-9.

5. EUVAC.NET. Measles surveillance annual report 2008. EUVAC. NET, pages 1-8. Available from: http://www.euvac.net/ graphics/euvac/pdf/annual_2008.pdf

6. Stefanoff P, Czarkowski MP. Unexpected rise in measles incidence in Poland in 2006 may be related to Ukrainian outbreak. Euro Surveill. 2006;11(26). pii=2990. Available from: http://www.eurosurveillance.org/ViewArticle. aspx?Articleld $=2990$

7. Bulletin: Infectious diseases and poisonings in Poland in 2008. National Institute of Public Health - National Institute of Hygiene - Department of Epidemiology, Chief Sanitary Inspectorate - Department of Communicable Diseases Control. Warsaw 2009.

8. Thierry S, Alsibai S, Parent du Châtelet I, on behalf of the investigation team. An outbreak of measles in Reims, eastern France, January-March 2008 -- a preliminary report. Euro Surveill. 2008;13(13). pii=8078. Available from: http://www. eurosurveillance.org/ViewArticle.aspx?Articleld $=8078$

9. Richard JL, Masserey-Spicher V, Santibanez S, Mankertz A. Measles outbreak in Switzerland - an update relevant for the European football championship (EURO 2008). Euro Surveill. 2008;13(8). pii=8043. Available from: http://www. eurosurveillance.org/ViewArticle.aspx?Articleld $=8043$

10. Marinova L, Muscat M, Mihneva Z, Kojouharova M. An update on an ongoing measles outbreak in Bulgaria, AprilNovember 2009. Euro Surveill. 2009;14(50). pii=19442. Available from: http://www.eurosurveillance.org/ViewArticle. aspx?Articleld $=19442$

11. WHO/UNICEF. Measles mortality reduction and regional elimination strategic plan 2001-2005 (WHO/V\&B/01.13). Geneva: World Health Organization and United Nations Children's Fund; September 2001. Available from: http://www. who.int/vaccines-documents/DocsPDF01/www573.pdf

12. Cohuet S, Bukasa A, Heathcock R, White J, Brown K, Ramsay $M$, Fraser G. A measles outbreak in the Irish traveller ethnic group after attending a funeral in England, March-June 2007. Epidemiol Infect. 2009;137(12):1759-65.

13. Noury U, Stoll J, Haeghebaert S, Antona D, Parent du Châtelet I, The investigation team. Outbreak of measles in two private religious schools in Bourgogne and Nord-Pas-de-Calais regions of France, May-July 2008 (preliminary results). Euro Surveill. 2008;13(35). pii=18961. Available from: http://www. eurosurveillance.org/ViewArticle.aspx?Articleld $=18961$

14. Anis E, Grotto I, Moerman L, Warshavsky B, Slater PE, Lev B, Israeli $A$. Measles in a highly vaccinated society: the 2007-08 outbreak in Israel. J Infect. 2009;59(4):252-8.

15. Stefanoff P, Orlikova H, Rogalska J, Kazanowska-Zielinska E, Slodzinski J. Mass immunisation campaign in a Roma settled community created an opportunity to estimate its size and measles vaccination uptake, Poland, 2009. Euro Surveill. 2010;15(17). pii=19552. Available from: http://www. eurosurveillance.org/ViewArticle. aspx?Articleld $=19552$

16. Makowka A, Gut W, Litwinska B, Santibanez S, Mankertz A. Genotyping of measles and rubella virus strains circulating in Poland in 2007. Euro Surveill. 2007;12(43). pii $=3295$. Available from: http://www.eurosurveillance.org/ViewArticle. aspx?Articleld=3295 